\title{
Total Scalp Replantation after Traumatic Avulsion
}

\author{
Kuldeep Singh ${ }^{1} \quad$ Krittika Aggarwal ${ }^{1}$ \\ ${ }^{1}$ Department of Plastic Surgery, Pt. Bhagwat Dayal Sharma PGIMS, \\ Rohtak, Haryana, India
}

Indian J Plast Surg:2020;53:311-312

Avulsion injuries are one of the traumatic injuries which occur due to tangential force and are difficult to reconstruct. Hence, scalp replantation remains the only ideal surgical modality. Warm ischemia time of 17 hours and cold ischemia time of 24 hours is considered standard. ${ }^{1}$ - Fig. 1 shows the anatomy of the scalp. We present the case of a 45 -yearold female who presented 8 hours after injury with scalp avulsion due to entanglement of head scarf (dupatta) in the motorized machine. The avulsed segment was brought after 1 hour of the presentation. Line of avulsion was-both eyebrows, root of nose, above ears, and occipital area. The plane of cleavage was loose areolar tissue. The preoperative photographs are shown in -Figs. 2 and -Figs. 3 . Through washing with normal saline, manual picking of visible debris was done, and hairs were trimmed all over the avulsed part. Left anterior branch of superficial temporal artery and right posterior branch of vein accompanying it were anastomosed using Nylon 8-0 under loupe magnification (4X) and general anesthesia by single team. No neural repair was done. The approximate blood loss was $400 \mathrm{~mL}$, postoperative hemoglobin recorded $11 \mathrm{~g} \%$. No blood transfusion was done. Temperature, skin color, and scratch test were used for clinical monitoring. Low-molecular weight dextran was given in postoperative period for 5 days. First dressing was done on day 2 and discoloration of the posterior part was noted. On day 4, debridement of necrosed area was done and left to heal by secondary intenton, as shown in - Fig. 4. After 1 year, she had normal hair growth, as shown in - Fig. $\mathbf{5}$.

Various authors have documented their experience. ${ }^{2-4}$ Usually, the line of avulsion is just below eyebrows, as in this case. However, avulsion at the level of medial canthal ligament has also been reported. ${ }^{2}$ Cervical spine injury is considered an absolute contraindication for scalp replantation. Malmande et al reported scalp replantation in a patient with suspected cervical spine injury and limited neck mobilization. ${ }^{5}$ We report this case to document the success even in nonideal conditions and emphasize the importance of attempting replantation even in peripheral hospitals.
Address for correspondence Krittika Aggarwal, MS, Mch, Department of Plastic Surgery, Pt. Bhagwat Dayal Sharma PGIMS, Rohtak 124001, Haryana, India (e-mail: krittika.agga@gmail.com).

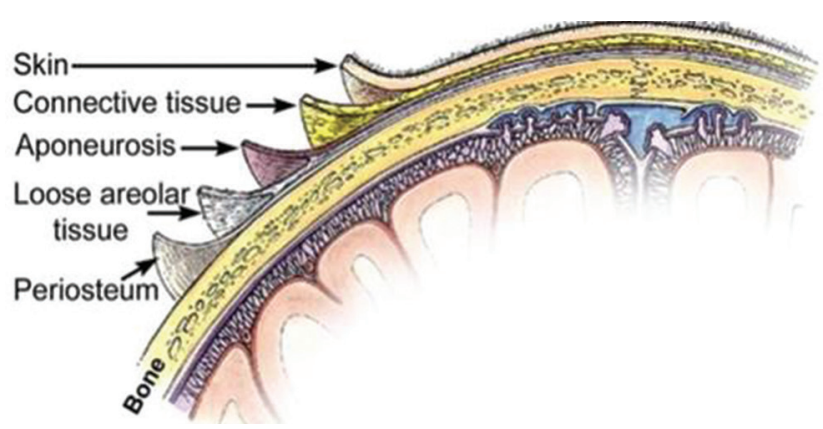

Fig. 1 Diagram showing layers of scalp.
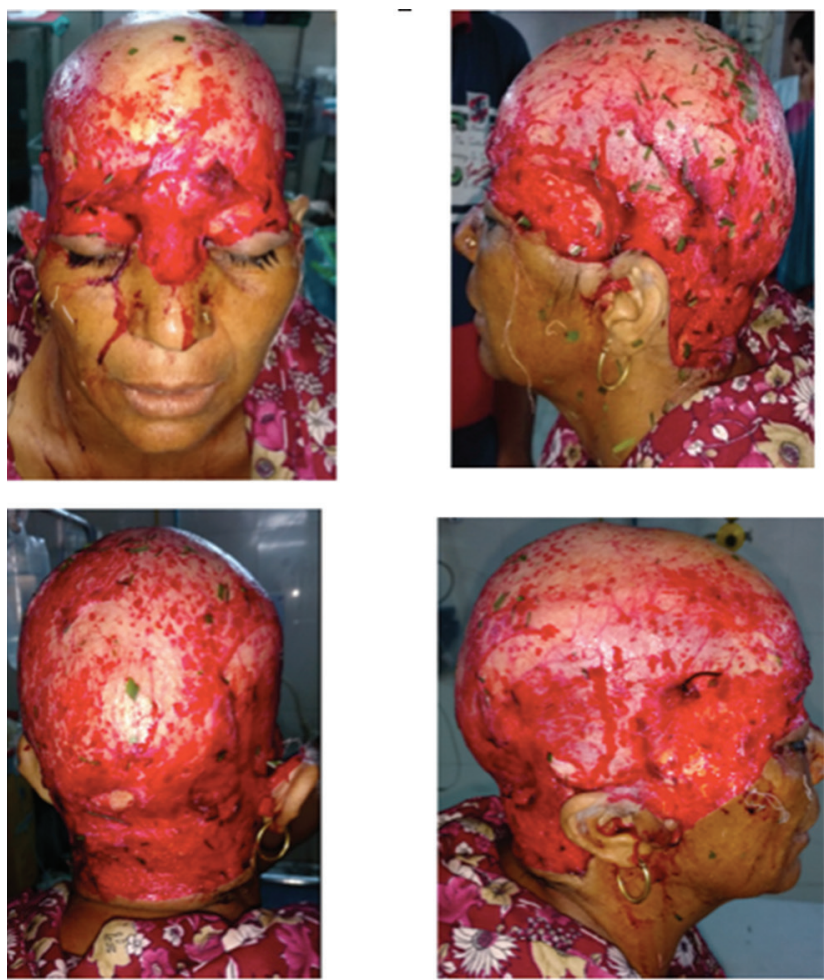

Fig. 2 Preoperative photographs showing the extent of avulsion.
DOI https://doi.org/

10.1055/s-0040-1716309

ISSN 0970-0358.
(C)2020 Association of Plastic Surgeons of India
License terms

(ㅇ)(1) $\Theta \circledast$ 

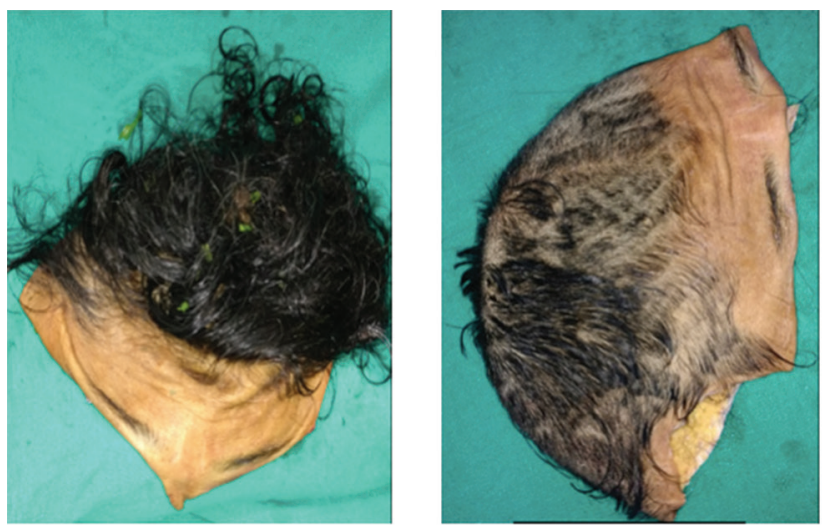

Fig. 3 Photograph showing avulsed scalp segment with eyebrows.

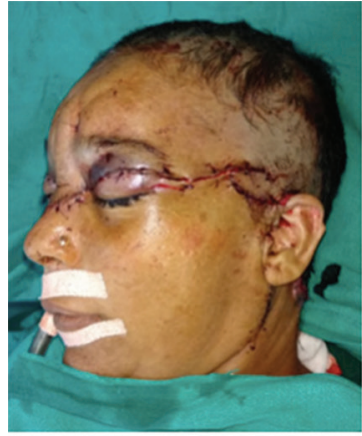

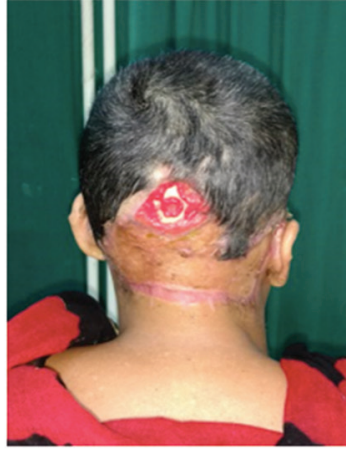

Fig. 4 Postoperative photograph showing (a) completed anastomosis, (b) segmental loss at occiput.

\section{Presentation at a Meeting}

Nil.

\section{Conflicts of Interest}

None declared.
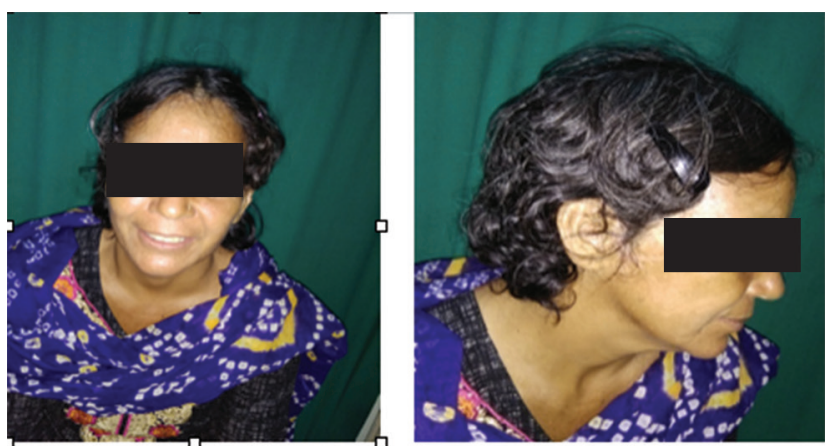

Fig. 5 Photograph showing postoperative results at 1 year.

\section{References}

1 Sirimaharaj W, Boonpadhanapong T. Scalp replantation: a case report of long ischemic time. J Med Assoc Thai 2001; 84(11):1629-1634

2 Sabapathy SR, Venkatramani H, Bharathi RR, D'Silva J. Technical considerations in replantation of total scalp avulsions. J Plast Reconstr Aesthet Surg 2006;59(1):2-10

3 Obed V, Thamas AB. Microsurgical reimplantation of the avulsed scalp. J Am Coll Surg 2017;225(4Supplement 2): e40-e41

4 Yin J-W, Matsuo JM, Hsieh CH, Yeh MC, Liao WC, Jeng SF. Replantation of total avulsed scalp with microsurgery: experience of eight cases and literature review. J Trauma 2008;64(3):796-802

5 Malmande V, Rao N, Biradar A, Bansal A, Dutt C. Scalp replantation in a cervical spine injury patient: Lessons learnt. Indian J Plast Surg 2018;51(2):243-246 